\title{
Vibration as a pitfall in pyrosequencing analyses
}

\author{
Helen Konrad ${ }^{1} \cdot$ Laura Schäfer $^{1} \cdot$ Hannah Sturm ${ }^{1} \cdot$ Lena Hördt $^{1} \cdot$ Thomas Bajanowski $^{1} \cdot$ Micaela Poetsch ${ }^{1} \mathbb{C}$
}

Received: 29 July 2021 / Accepted: 27 September 2021 / Published online: 12 October 2021

(c) The Author(s) 2021

\begin{abstract}
Since methylation analysis has become an important tool in forensic genetics, the reliability and credibility of the method must be ensured. After a successful validation and establishment of several pyrosequencing assays using a PyroMark® Q48 Autoprep instrument (Qiagen, Hilden, Germany), we decided to expand the method further purchasing a second instrument. But after initializing this second instrument side by side with the first, the majority of analyses failed (97 samples of 133 samples (73\%)). The number of error messages increased rapidly and the average RFU values decreased. After purchasing two anti-vibration weighing tables for the PyroMark ${ }^{\circledR}$ instruments and repeating the analyses under the same conditions and with identical samples the results improved considerably, 115 samples of 130 samples (88\%) showed successful and reproducible results. These findings demonstrate the impact of vibrations and percussions on PyroMark $® 48$ Autoprep performance and the reliability of methylation analyses.
\end{abstract}

Keywords Methylation $\cdot$ Methylation analysis $\cdot$ Pyrosequencing $\cdot$ Vibration $\cdot$ CpGs

\section{Introduction}

DNA methylation analysis is a method with increasing importance in forensic genetic research and casework [1, 2]. Especially, estimation of biological age by analysis of age-dependent $\mathrm{CpG}$ sites, but also body fluid identification by determining the methylation status of certain $\mathrm{CpGs}$, has become a relevant tool [reviewed by 3,4]. Several techniques could be employed for methylation analysis, e.g., massive parallel sequencing (MPS) [5], methylation-specific-PCR (MSP) [6], or pyrosequencing [7]. The reliability and credibility of results produced by these methods depend on the quality of the established assays as well as on the performance of the employed instruments. Here, we describe the impact of vibrations on the meaningfulness of results produced by a PyroMark ${ }^{\circledR}$ Q48 Autoprep (Qiagen, Hilden, Germany). For this purpose, identical samples have been analyzed under three different conditions.

Micaela Poetsch

micaela.poetsch@uk-essen.de

1 Institute of Legal Medicine, University Hospital Essen, Hufelandstr 55, 45122 Essen, Germany

\section{Material and methods}

\section{Samples}

The study comprised saliva, blood, and menstrual blood samples from different individuals of different age. All in all, 130 samples were collected in 2020 and 2021 in the Institute of Legal Medicine, University Hospital Essen, Germany.

\section{DNA extraction, quantification, bisulfite conversion, amplification, and sequencing}

DNA extraction was performed using DNA IQ Casework Pro Kit and Casework Extraction Kit in the Maxwell 16® instrument according to the manufacturer's instructions (Promega, Mannheim, Germany), resulting in an extraction volume of $50 \mu \mathrm{l}$. DNA concentration of samples was established by real-time PCR using the PowerQuant ${ }^{\mathrm{TM}}$ System (Promega) according to the manufacturer's instructions providing a reproducible and reliable detection threshold at least down to $25 \mathrm{pg}$ DNA [8]. Using $2 \mu \mathrm{l}$ DNA-containing solutions, each sample was analyzed in duplicates. Bisulfite conversion was performed applying MethylEdge Conversion System Kit (Promega) corresponding to the manufacturer's instructions with an increased elution volume of $20 \mu \mathrm{l}$. An initial DNA amount of $50 \mathrm{ng}$ was used in the conversion. 
DNA amplification of age estimation CpGs [9] as well as candidate $\mathrm{CpGs}$ for body fluid identification $[10,11]$ was done using PyroMark ${ }^{\circledR}$ PCR Kit (Qiagen) following the manufacturer's instructions, adapted to an increased number of 50 cycles. One of the two PCR primers was biotinylated.

Sequence analysis was established in a PyroMark ${ }^{\circledR}$ Q48 Autoprep instrument using the PyroMark ${ }^{\circledR}$ Q48 Advanced $\mathrm{CpG}$ Reagent Kit according to the manufacturer's instructions (Qiagen). Every sample and $\mathrm{CpG}$ site was analyzed at least twice.

\section{Experimental setups}

In the first setup, only one PyroMark® Q48 Autoprep instrument placed on a normal working bench was employed. In the second setup, another PyroMark ${ }^{\circledR}$ Q48 Autoprep instrument was installed side by side with the first one and both instruments ran simultaneously on a normal working bench. In the final setup, both instruments ran simultaneously in close proximity, but each one was installed on a separate anti-vibration weighing table. All 130 samples have been analyzed in every setup.

\section{Results and discussion}

\section{Reliability of data and DNA concentrations}

Due to the demand of downstream methods, especially bisulfite conversion, all samples included in this study showed a DNA concentration between 2.5 and $50 \mathrm{ng} / \mu \mathrm{l}$. For all three analysis setups, the same 130 samples were used, so that an impact of incomplete bisulfite conversion or differences in sample quality can be excluded.

\section{Evaluation strategy}

The instrument has three different quality parameters: failed, check, and passed. If a sample displayed a result in the category failed, it cannot be evaluated in most cases. Several error messages, a very low RFU (mean value $48 \pm 39$; see Table S1 for details), and a baseline drift typically occur in these samples. A sample with the result check is usually reliable. Nevertheless, there may still be error messages and only a medium RFU height (mean value $77 \pm 65$; see Table S1 for details), but generally, no baseline drifts are present. The best result is category passed that normally indicates high RFU values (mean value $114 \pm 47$; see Table S1 for details) without error messages.

The software generates two different categories of error messages to convey problems during analysis, general warnings and positions warnings.
General warnings usually appear in systematic problems, e.g., because of failed bisulfite conversion or a dispensation of drops with unusual shape.

Positions warnings indicate position-related problems, e.g., too low or too high peak height. Moreover, a baseline drift also may result in a positions warning.

\section{Sequence analysis}

In the first setup, one instrument PyroMark ${ }^{\circledR}$ Q48 Autoprep (Qiagen) was used and several assays in context of age estimation could be established and validated [9]. More than three quarter of analyses demonstrated reliable and reproducible results categorized as either check or passed by the instrument software (Table 1). Nevertheless, we observed a few error messages and a rather low median RFU height (78 \pm 65 ), but generally, no baseline drifts and warnings were present (Table S1).

In order to expand this kind of analysis and to establish further assays in context of body fluid analysis, a second PyroMark ${ }^{\circledR}$ Q48 Autoprep (Qiagen) was purchased. This was installed by a Qiagen's technician side by side with the first instrument. He confirmed that this placement would not lead to any problems with data evaluation. However, using both instruments simultaneously side by side (setup 2), the main part of samples in both devices was qualified as failed (97 samples of 130 samples (75\%) (Table 1)). The number of error reports and baseline drifts increased rapidly and the average RFU decreased considerably (Table S1). Looking for possible causes, we found a very short hint at possible problems with vibrations on page 29, 4.2.1 Installation site of the PyroMark® Q48 Autoprep User Manual [12]. Since vibrations are also a known problem for other high-end instruments (e.g., MiSeq FGx ${ }^{\mathrm{TM}}$ Instrument, 13), two antivibration weighing tables (Bosche Wägetechnik, Damme, Germany) were purchased (Figure S1). A heavy stone, balanced on rubber, protects the PyroMark ${ }^{\circledR}$ Q48 instrument from vibrations transmitted through the floor or along the working bench.

After performing sequence analysis with both instruments placed on anti-vibration weighing tables (setup 3),

Table 1 Evaluation of pyrograms after sequence analysis in three different setups

\begin{tabular}{llll}
\hline $\begin{array}{l}\text { Sequence anal- } \\
\text { ysis quality }\end{array}$ & One instrument & $\begin{array}{l}\text { Two instruments } \\
\text { side by side } \\
(n=130)\end{array}$ & $\begin{array}{l}\text { Anti-vibration } \\
\text { weighing table } \\
(n=130)\end{array}$ \\
\hline Passed & $42(32 \%)$ & $17(13 \%)$ & $\mathbf{1 1 5}(\mathbf{8 8} \%)$ \\
Check & $\mathbf{5 9 ( 4 5 \% )}$ & $16(12 \%)$ & $12(9 \%)$ \\
Failed & $29(22 \%)$ & $\mathbf{9 7}(\mathbf{7 5} \%)$ & $3(2 \%)$ \\
\hline
\end{tabular}

Deviations from $100 \%$ are caused by rounding. For each setup, values in the category with the majority of results are printed in bold 
the results improved considerably and surpassed even those of our first experiments. More than $97 \%$ of analyses were evaluated as check or passed (Table 1). In the majority of results, pyrograms showed no warnings or baseline drifts and high RFUs could be reached especially in the category passed (Table S1).

The manual of the PyroMark® Q48 suggests a lot of possible sources for a bad quality of results/pyrograms, e.g., failed bisulfite conversion, a dispensation of drops with unusual shape, or too low/high peak height. However, the results of this study propose vibration as the main error source, since the presence or absence of vibration is the only difference between the three experimental setups due to use of identical samples, reagents, and procedures. Moreover, for setup one, no differences between the two instruments could be observed (data not shown). The principle of pyrosequencing is based on a locus and time-dependent detection of light (chemo luminescence). Therefore, it is understandable that any moving of the instrument during a run has an impact on the quality of the results. Due to occurrence of vibration, time and locus could be (slightly) out of alignment and the time- and locus-dependent detection fails. As a result, the expected RFU values will not be achieved. Due to the increasing number of general warnings, it can be concluded that the injectors are not performing properly under the influence of vibrations and may produce drops of unusual shape.

\section{Conclusion}

The results of this study clearly demonstrate that vibration is a major problem for pyrosequencing instruments leading to unreliable and not reproducible outcomes. We recommend a more assertive description of these phenomena in the manual of the instrument, probably including the advice to install the devices only in vibration-free environments.

All samples were obtained after informed consent and with approval of the Medical Ethics Committee at the University of Duisburg-Essen in accordance with the Declaration of Helsinki and national laws (ethic vote numbers: 16-7113-BO, 21-9843-BO).

Supplementary Information The online version contains supplementary material available at https://doi.org/10.1007/s00414-021-02716-7.

Funding Open Access funding enabled and organized by Projekt DEAL.

\section{Declarations}

Conflict of interest The authors declare no competing interests.

Open Access This article is licensed under a Creative Commons Attribution 4.0 International License, which permits use, sharing, adaptation, distribution and reproduction in any medium or format, as long as you give appropriate credit to the original author(s) and the source, provide a link to the Creative Commons licence, and indicate if changes were made. The images or other third party material in this article are included in the article's Creative Commons licence, unless indicated otherwise in a credit line to the material. If material is not included in the article's Creative Commons licence and your intended use is not permitted by statutory regulation or exceeds the permitted use, you will need to obtain permission directly from the copyright holder. To view a copy of this licence, visit http://creativecommons.org/licenses/by/4.0/.

\section{References}

1. Kader F, Ghai M (2015) DNA methylation and application in forensic sciences. Forensic Sci Int 249:255-265

2. Sabeeha HS (2019) Forensic epigenetic analysis: the path ahead. Med Princ Pract 28:301-308

3. Kader F, Ghai M, Olaniran A (2020) Characterization of DNA methylation-based markers for human body fluid identification in forensics: a critical review. Int J Legal Med 134:1-20

4. Parson W (2018) Age estimation with DNA: from forensic DNA fingerprinting to forensic (epi)genomics: a mini-review. Gerontology 64:326-332

5. Suzuki M, Greally J (2013) Genome-wide DNA methylation analysis using massively parallel sequencing technologies. Semin Hematol 50:70-77

6. Lin Y, Tsai L, Lee J, Liu K, Tzen J, Linacre A, Hsieh H (2016) Novel identification of biofluids using a multiplex methylationspecific PCR combined with single-base extension system. Forensic Sci Med Pathol 12:128-138

7. Eckhardt F, Lewin J, Cortese R, Rakyan V, Attwood J, Burger M, Burton J, Cox T, Davies R, Down T, Haefliger C, Horton R, Howe K, Jackson D, Kunde J, Koenig C, Liddle J, Niblett D, Otto T, Pettett R, Seemann S, Thompson C, West T, Rogers J, Olek A, Berlin K, Beck S (2006) DNA methylation profiling of human chromosomes 6, 20 and 22. Nat Genetics 38:1378-1385

8. Poetsch M, Konrad H, Helmus J, Bajanowski T, von WurmbSchwark N (2016) Does zero really mean nothing?-first experiences with the new PowerQuant(TM) system in comparison to established real-time quantification kits. Int J Legal Med 130:935-940

9. Pfeifer M, Bajanowski T, Helmus J, Poetsch M (2020) Inter-laboratory adaption of age estimation models by DNA methylation analysis-problems and solutions. Int J Legal Med 134:953-961

10. Lee H, An J, Jung S, Oh Y, Lee E, Choi A, Yang W, Shin K (2015) Genome-wide methylation profiling and a multiplex construction for the identification of body fluids using epigenetic markers. Forensic Sci Int Genet 17:17-24

11. Forat S, Huettel B, Reinhardt R, Fimmers R, Haidl G, Denschlag D, Olek K (2016) Methylation markers for the identification of body fluids and tissues from forensic trace evidence". PLoS One 11:e0147973

12. PyroMark®Q48 Autoprep User Manual https://www.qiagen.com/ $\mathrm{nl} /$ resources/resourcedetail?id=650a0c13-3b8e-4a77-b433-6b1e5 0b9525a\&lang $=\mathrm{en}$

13. MiSeq FGx ${ }^{\mathrm{TM}}$ Instrument Site Prep Guide 2018. https://verogen. com/wp-content/uploads/2018/07/MiSeq-FGx-Site-Prep-GuideVD2018012-A.pdf

Publisher's note Springer Nature remains neutral with regard to jurisdictional claims in published maps and institutional affiliations. 